\title{
EDUCATING STUDENTS TO ENHANCE CULTURAL HERITAGE: "LITTLE ARCHAEOLOGISTS WITH A 3D PRINTER" A HERITAGE EDUCATION PROJECT
}

\author{
Severo Cardone ${ }^{1}$
}

\begin{abstract}
This school project is about Cultural Heritage Education and involves students attending the first year of secondary school. It has the purpose of experimenting with an interdisciplinary education approach which aims at stimulating students' interest in local history and cultural heritage, through the use of multimedia tools, 3D graphics and printing programs, and the experience of new teaching and learning strategies such as Problem-Based Learning (PBL), learning by doing and peer education. Enhancing the laboratory experience, teamwork and gamification, students can simultaneously negotiate contents/topics and co-build new disciplinary knowledge (closely related to the content and learning objectives indicated in the curriculum of each involved discipline). They will acquire technical skills (Information technology, multimedia and archaeology skills) and cross cultural competences (such as key competences, life skills and other soft skills) and they will develop an encouragement and protection kind of mentality related to cultural heritage, that is essential to feel engaged in a community life and acquire active and democratic citizenship skills.
\end{abstract}

Keywords: heritage education, Problem-based Learning (PBL), soft skills, 3D printing.

\section{Needs analysis and main educational objectives}

Nowadays, cultural heritage is attracting public attention again, so that the number of visitors to museums, art galleries and archaeological parks tends to increase year by year progressively. However, it is very common to find a passive, quick and superficial fruition in the average visitor, which does not allow him/her to fully understand the meaning and value of the cultural heritage he has enjoyed. This is a very common phenomenon that unfortunately generates negative educational repercussions: on museum fruition, which is hasty, inattentive and "poor" from a cognitive, emotional, aesthetic and relational point of view; as regards museum attendance, for example, a student who perceives the visit to the museum as tedious and unimportant, will hardly come back to a museum with his/her family when adult; as regards the promotion of active and democratic citizenship, if we "recognize"

1 Postdoctoral Researcher in Cultural Heritage and Education at the University of Foggia. severo.cardone@unifg.it. 
ourself in the observed heritage and learn to care about it, we build our sense of belonging to a community and we develop a protective mentality.

As regards this background many problems arise, such as educating different kinds of public visitors to a correct fruition of museum collections and in general of cultural heritage. It is clear that an effective education to cultural and museum heritage must start at school and be able to involve and "tie" all subjects together (interdisciplinary teaching), to link different school levels and grades and, above all, it needs to reinforce and progressively grow up through the planning of visits and laboratory activities, and stimulating, engaging and interactive education experiences through the use of digital tools (such as software and 3D printers), multimedia devices and Information and Communications Technology.

Educational institutions undoubtedly represent a privileged partner for museums: due to the strong analogy between the two types of institutions, museums are educational and culture promotion places as well as schools; moreover, students have always been the main visitors of museums; and the school learning process of disciplinary content at school can start from the study of finds, works and collections of local museums (heritage education). By accepting this new educational vision, visits to the museum will no longer be perceived as a "getaway" from the school's daily life, rather the intermediate or final stage of training projects perfectly integrated into school planning, and planned through close collaboration between teaching staff and museum educators and it is able to achieve precise education and learning outcomes subject to an assessment (ex ante, in itinere, ex post).

The main objective is essentially to invest in a Heritage Education project: an active, interdisciplinary education, that is perfectly integrated into school curriculum and that can contribute to the development of rich, responsible identities who are sensitive to the process of safeguarding and enhancing cultural heritage and aware of their community membership and, at the same time, they are able to enrich themselves through the comparison with cultural "diversity".

Particularly, it should be remembered that, as early as 1998, the Council of Europe, with the Recommendation N.R. (98) 5 on "Heritage Education" intended to involve Member States in adopting specific legislative and financial measures capable of encouraging and facilitating the implementation of projects focusing on promoting an awareness of cultural heritage among young people, irrespective of their financial background:

heritage education means a teaching approach based on cultural heritage, incorporating active educational methods, cross-curricular approaches, a partnership between the fields of education and culture and employing the widest variety of modes of communication and expression [...]; Initiatives taken by schools, universities, cultural heritage professionals and associations and their governing bodies should be encouraged and facilitated [...]; Heritage education presupposes a link with school programmes and appropriate training for teachers [...]; All young people, irrespective of their family 
or financial background, should be able to take part in heritage education activities [...].

The "Council of Europe Framework Convention on the Value of Cultural Heritage for Society", signed in Faro on 27 October 2005 and entered into force in 2011, underlines that knowledge of cultural heritage is part of the "right" of European citizens to participate actively to social and cultural life, a resource able to effectively contribute to the development of the person and the promotion of intercultural dialogue. Specifically, in the section dedicated to the "contribution of cultural heritage to society and human development" it is explicitly indicated that the need to encourage an ethical reflection on how to consider heritage with respect for cultural diversity and to recognize an essential resource that can foster peaceful coexistence and social cohesion through mutual understanding.

Taking this perspective, Adriana Bortolotti, Mario Calidoni, Silvia Mascheroni and Ivo Mattozzi $(2008$, p. 47) underline that a proper education to heritage must enable the development of identity awareness and community membership, but at the same time, it must be able to encourage a constructive dialogue on diversity issues:

heritage will therefore be crucially important in education to democratic citizenship, seen as active and constructive dialogue with the other, whether it belongs to different territories and cultures, or it introduces different instances while being a member of the same community. [...] Heritage can be a powerful support for enriching the identities of citizens of other cultures within a community.

Heritage education projects therefore aim at achieving a variety of educational and teaching objectives that can contribute to the holistic and multidimensional shaping of individuals/citizens: to foster an affective predisposition towards cultural heritage (affective education); to critically interpret the value and significance of the observed cultural heritage (education to understanding); to recognize oneself in the observed cultural heritage seen as a set of representative traces the history, identity, values and traditions of a community (education to recognition); to educate to beauty and aesthetically appreciate the observed heritage (aesthetic education); to acquire a protective mentality (education to protection and enbancement); to develop an active, responsible and sensitive attitude to cultural and social life (education to active citizenship); to recognize and enhance cultural diversity with a view to a proper education to intercultural dialogue and peaceful coexistence (education to democratic citizenship); to activate different forms of intelligence and promote the development of a critical, creative, divergent thinking and open to change (developmental education).

\section{Expected results in terms of competencies and disciplinary learning outcomes}

To promote and elicit the students' learning and proper use of the local cultural heritage of the Civic Museum of Foggia (archaeological finds of Daunian population) through an interdisciplinary learning approach will enable participants 
to acquire or strengthen specific disciplinary content, develop technical skills related to new 3D technologies and archaeology and train multiple soft skills. In particular, as regards the individual disciplines involved in the project (art, computer science, geography, history and mathematics), the expected results in terms of skills and learning outcomes will be the following:

\section{ICT and technology}

To use technology and multimedia as supporting tools that can foster knowledge by creating a highly collaborative and interactive student-centered learning environment based on the needs and characteristics of learners.

To use computer, multimedia and digital tools in a conscious, responsible and creative way.

To develop technical-professional skills related to the use of new 3D technologies (hardware and software).

To create complete graphic designs reproducing some Daunia archaeological finds located in the Civic Museum. These projects, besides being printed in the classroom and exhibited at the school, will be shown to visitors in special digital archives on dedicated websites or portals and can be downloaded by those who have a 3D printer and want to use graphic products ready for printing.

To promote and support the creation of a community of practice based on the development of critical thinking, the negotiation of meaning, and the co-building of knowledge.

\section{Art}

To increase the students' knowledge about local territory and heritage with a specific insight into Dauni civilization.

To learn observing, reading, and describing archaeological finds within the Civic Museum of Foggia and with the support of an expert, applying the principles of visual perception with particular attention to the colours, points, lines and geometric shapes represented in the selected finds.

To recognize in the shapes and decorations of the archaeological finds the expressive meaning and the main elements of visual grammar.

To compare some archaeological finds and recognize the main differences (materials, styles, shapes, colours, decorations, use etc.).

To recognize and manipulate different materials (chalk, painting colours, clay etc.) by identifying the main features and thinking about possible applications.

To move in the exhibition space of the museum and recognize paths, halls and criteria for exhibition.

To experiment with a process of learning strongly focused on sensory dimension enhancement (hands-on methodology), on workshop activities (learning by doing) and artistic education (to educate to creative and divergent thinking).

To learn and experience the main techniques of digging, cleaning and cataloguing archaeological finds even through simulations (role playing).

Subjectively reinterpret the findings and artefacts observed and 3D printed using different materials and graphic, pictorial and decorative techniques. 


\section{Geography}

To learn how to read and interpret geographic maps, charts, photographs, movies, satellite images and captions featuring Daunia's territory and linked to Daunia's civilization.

To learn how to use analysed information, data, and finds to produce an in-depth geographic report.

To be able to recognize the shapes of landscape and the main characteristics (origins, language, traditions, society, economy, history, culture, crafts - etc.) of the populations that have lived in the territory of our province, with a particular focus on Daunia's civilization.

Enhance students' concepts of landscape, border, region, province, state.

\section{Mathematics}

To recognize and graphically represent points, lines, segments, angles, curves, polygons, and the main geometric figures found in the selected finds/artefacts.

To be able to calculate dimensions, quantities, measures, and recognize similarity in geometric shapes.

To be able to use the suitable tools (even digital tools) to draw and create geometric shapes with precision.

\section{History}

To learn how to use different types of historical sources.

To recognize the spatial and temporal dimension related to the development of Daunia's civilization.

To learn how to read and interpret historical maps, documents, data, tables, charts, captions.

To identify and describe relationships and links among events by recognizing cause and effect relationships.

To be able to write a historical report.

To learn how to clearly and accurately present the contents and skills learned during project activities.

\section{Pedagogical theories supporting the education heritage project}

"Education requires total involvement in the process that is not a transmission process any more, but a process of interpretation and knowledge building, with an emotional or affective inevitable component, which modifies and transforms the learning process and produces a change in attitudes, behaviours and thoughts" (Visser Travagli, 2006, p. 16). Starting from this definition, among the available theories about knowledge and learning, the project team decided to refer to a constructivist approach Jean Piaget, Lev Vygotskij (2006), Jerome Bruner (1988; 1992; 2000), Howard Gardner (1999; 2005), George Hein (1995; 1998) and other education experts] that is particularly well suited to educational goals that can be acquired in a formal learning context, such as the school, but also in an informal 
context, such as the museum. Pedagogical constructivism considers the student from a passive recipient of information to an active participant in the learning process, and he/she is able to interact and communicate constantly with the environment to negotiate meanings and co-build knowledge. In short, the constructivist model says that learning is a process with the following characteristics:

- active, through which the visitor builds meaning through a physical, cognitive, emotional, affective, relational, multisensory (multidimensional) involvement;

- situated, in a context (such as the museum or school) whose specific features have a decisive influence on the learning process;

- social or collaborative, the personal attribution of meaning to experience is a socially mediated activity; you can learn it through the relationships with others (teachers, classmates, family, friends, museum educators, visitors) but also through the support of technologies (such as the computer or the $3 \mathrm{D}$ printer) and other tools or cultural mediators that mediate our cognitive interactions and foster the co-building of knowledge;

- meaningful, the visitor learns more easily if he/she is able to easily connect to previous life experiences or create links to prior knowledge and references to previously learned material;

- learner/visitor-centered and based on their specific characteristics and needs, in the process of teaching-learning the learner centrality replaces the teacher one.

This pedagogical approach has changed teaching methods, tools and supports, and above all the role of the teacher/museum educator who becomes less important in the learning process and assumes the role of a supporter or facilitator (scaffolding) supporting or helping the learner to consciously and responsibly selfmanage the learning process, share hypotheses and interpretations, and gradually reach a critical understanding of knowledge and experience. The task of the teacher/ educator is no longer centered on transferring pre-packaged messages, but rather it aims at facilitating comparisons, exchanges, metacognition, negotiation of meanings, adapting the lesson or the visit at the museum to students' learning time and style, always allowing them to create connections with reality and encouraging students to engage in dialogue, both with the teacher and with one another, to provide feedback, formulate imaginative hypotheses, experiment with what they have heard or observed.

Adopting this pedagogical perspective, in heritage education projects the museum can become a decentralized classroom for the school, assuming the role of a relational context and learning environment which is able to dialogue and cooperate with the school and effectively contribute to the holistic education of the student-person through the following aspects: discovering the multiple levels of interpretation of exposed works of art, activating different forms of intelligence, soft skills development, use of all senses, the possibility of experimenting highly 
interactive and learning-based workshop activities (learning by doing). On this issue, Cecilia De Carli (2003, p. 105) reminds us that

the museum's experience in particular allows a relationship between disciplinary learning and building of cross-curricular competencies, between codified knowledge and experience, enhancing the research dimension. A museum that knows how to communicate with the school in this direction not only performs a task that is functional to the visibility of its specific purpose of scientific and didactic research and communication, but also it promotes the work of the school pursuing the aim of a continuous reorganization, systematization, mediation and reinterpretation of knowledge.

To organize a museum experience that can arouse curiosity, marvel and involve visitors to achieve positive results not only in cognitive terms (supporting and reinforcing knowledge acquired in the school context), but also from an emotional, affective, aesthetic and sensory point of view that is essential for the student's development and keeps him/her from perceiving the museum as a "boring" and "distant" space from his/her own culture. On the contrary, museum could be perceived as an educational and entertaining context, which is popular among families and where you can meet friends or meet other people who can educate their eye in perceiving and appreciating beauty and where you can develop new skills and mental abilities needed not only to get closer to art but above all to critically understand the complexity of contemporary society.

Benjamin Bloom (1979), an educational psychologist, focused on how the learning process becomes multidimensional when it is able to embrace not only the cognitive dimension but also the emotional dimension that allows us not only to acquire the information in the environment (assimilation) but also to link them "significantly" to memories, experiences, people of our lives (accommodation). In this regard, the metaphor of the "oven" used by Alberto Angela (2008, p. 39) is very important to highlight the importance of the emotional and affective dimension in the learning process: "cognitive learning is the blade of the baker that puts the bread in the oven while emotional learning is the heat of the oven that makes the bread rise and solidify. They need each other".

As for the importance of the aesthetic and sensorial dimension, American philosopher and pedagogue John Dewey (1995), in his work "Art as Experience", faces the complex relationship that arises between art, experience and education. Dewey argues that it is necessary to restore a continuity between art and everyday experience, art is an educational experience that can be not only an aesthetic enjoyment as an end in itself, but it can educate the individual to a critical, open, divergent thinking that is capable to enhance the ability to act in everyday life with efficiency and responsibility, so the artistic experience is not detached from reality but it is able to intensify the meaning of everyday life. Maria Montessori (2000), on the other hand, emphasizes that aesthetic and moral education can be promoted through proper sensory education because "beauty is in harmony, not in contrasts, and harmony is affinity, so sensory finesse needs to perceive it" (pp. 162-163). In particular, in the process of sensory education of children, an irreplaceable role is 
covered by touch and by hand (hands-on approach), a "prosthesis" of the mind that allows children to know better themselves and others, to explore the world, to try to experiment and thus to learn continuously.

According to Bruno Munari, art education must also have a "social" value, it must allow students to develop a personal point of view, critically interpret reality, avoiding cultural conditioning and thus mass thought expressed by society. In "Fantasia" (1977), Munari focuses on how creative and design thinking development in children can be favoured by the ability of children to interact with other children and create connections and relationships with what he already knows: children are trained by touching, manipulating, listening, drawing, experimenting with what he is observing they increase their experience and knowledge of others, context and reality. Their imagination, imagination and creativity can be trained through suitable sensorial, aesthetic and relational education.

\section{Project Description (target group, purposes, phases)}

This heritage education project", called "Little Archaeologists with a 3D printer", is addressed to the first two grades of secondary school (school year 2017-2018) of "Istituto di Cultura e Lingue Marcelline" of Foggia (Apulia, Italy) and involves thirty-seven students. Through the experimentation of an interdisciplinary teaching approach (school subjects are Art, Geography, History and Maths), the participating students will be stimulated to discover their territory and local cultural heritage through the use of multimedia tools, 3D graphics and printing programs and the use of active teaching strategies such as Problem-Based Learning (PBL), brainstorming, peer education, learning by doing, role-playing and hands-on learning approach. In particular, by enhancing workshop, group, and game experience, students will progressively acquire reflection abilities and critical thinking, and will be able to negotiate meaning and build new knowledge related to disciplinary knowledge (considering content and learning objectives indicated in the curriculum of each discipline involved). At the same time interaction, multisensory approach and "experimenting" through the workshop activities will enable the learners to develop technical skills (computer, multimedia, archaeological, and artistic skills) and cross-curricular competences (such as key competences, life skills and other soft skills).

With regard to the Recommendation of the European Parliament and of the Council of 18 December 2006, Member States are encouraged to promote the development of "key competences for lifelong learning" for young people. These are skills that citizens must have for their personal fulfilment, social inclusion, active

2 The project team coordinated by prof Stefania Tetta (headteacher of Istituto di Cultura e di lingue Marcelline of Foggia) is composed by the following teachers and researchers: Stefania Fréjaville (Art teacher and manager of the project), Antonella Santino (Geography teacher), Rosario Biasco (History teacher), Michele Robusto (Maths teacher), Francesca Capacchione (archaeologist, museum educator at Civic Museum of Foggia), Severo Cardone (PhD in Cultural Heritage and Education at the University of Foggia, research project supervisor). 
citizenship and career opportunities in our knowledge-based society. These include "Digital Competences" and knowledge, skills and attitudes related to "cultural awareness and expression" that can be acquired through expression, evaluation and appreciation of works of art:

Skills relate to both appreciation and expression: the appreciation and
enjoyment of works of art and performances as well as self-expression through
a variety of media using one's innate capacities. Skills include also the ability
to relate one's own creative and expressive points of view to the opinions
of others and to identify and realise social and economic opportunities in
cultural activity. Cultural expression is essential to the development of
creative skills, which can be transferred to a variety of professional contexts.
A solid understanding of one's own culture and a sense of identity can be
the basis for an open attitude towards and respect for diversity of cultural
expression. A positive attitude also covers creativity, and the willingness to
cultivate aesthetic capacity through artistic self-expression and participation
in cultural life (Official Journal of the European Union, 2006).

This project is composed of ten phases that will be carried out in nine months, from October 2017 to June 2018:

Phase 1) Project and research team presentation (phases, learning objectives, educational goals, expected outcomes, planned activities, assessment tools). In order to better understand pre-knowledge, expectations and motivations of each student, even in the perspective of in itinere effective redesign, a questionnaire will be given or individual interviews will be conducted.

Phase 2) For this phase, it is desirable to use an active learning approach such as Problem-based Learning (Lotti, 2007; Barrows \& Tamblyn, 1980), "a learning method that is used in a small group led by a tutor who acts as facilitator and proposes realistic but incomplete problems to students who discuss in group to solve the problem faced" (Lotti, 2007, p. 13). Using PBL the teaching-learning process is student-centered, learning takes place in small groups, teachers play the role of facilitators (scaffolders), problems presented to the group represent the organizational device and a motivational impulse for learning process that must be self-directed and based on acquiring skills such as problem solving. This method will be used in two distinct days.

First meeting - In plenary, a "case" or problem, that is realistic and built as clearly as possible, with a degree of complexity suitable for students' pre-knowledge, with interdisciplinary learning features and objectives (the text of the problem must be formulated in order to be related to the study of the curriculum modules of each discipline involved in the project. The case is an additional incentive for the following steps: $\operatorname{step} n$. 1) to introduce the main topic of heritage education and start with the students the analysis and discussion of unclear terms and concepts that are not immediately understandable, if the answers formulated by the students will not be satisfactory, unknown or unclear words will be written on a blackboard; step $n$. 2) to encourage questions related to the discussed (brainstorming); step $n$. 3 ) to group the questions into different homogeneous areas and write them on the blackboard; 
step $n .4$ ) to stimulate the group to answer the emerging questions (socio-cognitive conflict and cognitive dissonance); step n. 5) to plan study objectives and assign research tasks (showing sources that can be used). Students will be assigned specific questions that are still unanswered, and it will be up to them to provide correct answers through individual study (even in small groups) and use of specific sources (books, movies, websites, photographs, maps, interviews to experts etc.).

Second meeting - After individual study and research activities (step $n . \sigma$ ), students in plenary meeting will share the acquired information and data, even at this stage the students speaking about the work they have done and the strategies put into practice they learn from each other; in this phase of the PBL it will be the teacher-tutor's task to synthesize the acquired information, verifying that they are able to provide exhaustive answers and encourage group discussion in order to promote a meaning negotiation process and knowledge co-construction in the group (step $n$. 7). If some questions are still unexplored or there are still some doubts in the group, the teachers involved in the project will be able to provide disciplinary insights aimed at removing any further doubt. At the end students will have all the information they need to solve the case or problem initially proposed (step n. 8). Finally, an assessment phase of the group's work and engagement of each individual student in the resolution of the case or problem will be started (step n. 9 and $n .10$ ).

Phase 3) After the disciplinary in-depth study that is "preliminary" to the museum visit, the archaeologist's profession will be explained by a museum educator specialized in archaeology, (Who is he/she? What are his/her main tasks? Which tools does he/she use? What are his/her professional skills?). This will certainly not be a traditional lesson, and even in this case the students will "interview" the archaeologist by asking questions, sharing reflections, formulating hypotheses and negotiating essential meanings to reach a critical understanding of the archaeologist's profession and the importance of protecting and enhancing cultural heritage.

Phase 4) In the first part of the guided tour at the Civic Museum of Foggia, students will have the opportunity to meet some museum educators who, through movies, photographs and worksheets, will show them the main phases that characterize an archaeological excavation. In the second part of the visit, the educators will guide the participants in the rooms of the Civic Museum (archaeological section) showing them a selection of original finds of Daunian population displayed in the archaeological section; students will also see, touch and manipulate faithful reproductions of original archaeological finds in order to better understand their features (hands-on sensory approach). During the exploration and observation of the finds, the students will be invited to take photographs, to take notes on their personal journal, and constantly interact with the museum educators. Once they are back in class, teachers will have to support students in sharing in group curiosities, doubts, reflections, interpretations that can lead them to "focus" on the experience and create connections to the content and learning objectives of the individual disciplines. 
Phase 5) At school, with the support of museum educators, a workshop activity (learning by doing) will be carried out for the production of clay artefacts that have to be similar to the ceramic artefacts observed during the museum visit. Through the use of specific tools and materials, students will first design clay jars with the same technique used in the prehistoric time and then they will decorate them with colours, geometric decorations and themes that are typical of Daunian pottery. Within the learning process, this first workshop activity is very significant because it will allow participants to "experience" what they have previously observed in the museum's showcases, making continuous connections to the previous experience of fruition; the ability to test creatively allows students to verify the accuracy and usefulness of the knowledge learned in the museum context.

Phase 6) After the clay modelling workshop (hands-on methodology), the next stage provides for the use of 3D graphics and printing programs. Specifically, participants, through team-based workshops to be held at school during several meetings, have to draw, graphically design and finally create, through the use of a 3D printer, the faithful reproductions of some artefacts (jugs, askos, bucket, cups, pots etc.) of the collection exhibited at the Civic Museum. The learning objectives of this phase are the following: to consolidate and strengthen the acquired knowledge (historical, archaeological and related to the individual disciplines) through highly interactive tools (3D software and hardware); to foster greater mastery and awareness in the use of new multimedia educational technologies (edutainment); promoting soft skills development and experimenting with cooperative peer education. The activity will enable the students group to start an analytical study of the forms, colours and materials used by the Daunians to produce ceramic artefacts, that is preliminary to the following phases of the project: simulation of an archaeological excavation with following cleaning and cataloguing of the finds; critical reinterpretation of 3D manufactured items.

Phase 7) After the 3D printing phase, a simulated archaeological excavation activity (role-playing) will follow in the classroom. Some tanks will be prepared with several layers of soil (made of sand and dark limestone lenses); inside fragments of finds and the tableware 3D printed will be added. Students will be divided into groups and provided with a kit containing the traditional tools used by archaeologists in excavations: cleaning brushes, small trowels, spoons, buckets and plastic pallets, that are essential for sifting the soil, recovering and cleaning the fragments or finds. Each of the participants will be given a specific and different task, closely related to that of the other group members, so the students will need to collaborate and cooperate to achieve a common learning goal. While excavating and unearthing finds, the documentation and cataloguing phase begins, until the final interpretation of the data is obtained. The excavation will allow students to locate the finds in an accurate spatial and temporal sequence, which will allow some aspects of Daunian population (culture, society, work, values, traditions etc.) to stand out. Although its playful features, excavation simulation activity, subject to the observance of accurate methodological rules, aims at developing not only technical skills (related to the archaeologist profession) but also multiple soft skills 
such as teamwork, problem solving or decision-making, but also communicativerelational skills, investigative spirit, visual and tactile perception.

Phase 8) 3D-printed templates used for excavation and restoration simulations can be subjectively "reinterpreted" using the "modern" decorative and artistic techniques that can transform copies of the finds into pop artwork characterized by a different meaning than the ancient one (meaning making process).

Phase 9) At the end of the workshop activities, a collective exhibition will be organized at the school premises to show visitors the works of art made by the students and the learning, educational and teaching objectives achieved through this heritage pedagogy project, which provides for an additional scientific publication (communication and dissemination of results).

Phase 10) The project, at all phases, involves the use of specific assessment tools (questionnaires, focus groups, thinking aloud, personal journals, observation, photography, products of workshop activities, comment cards, digital storytelling) which allow the project team to constantly monitor the results achieved in terms of experience enjoyment, disciplinary learning objectives, acquired competences and educational implications.

\section{References}

ANGELA, A. Musei (e mostre) a misura d'uomo. Come comunicare attraverso gli oggetti. Roma: Armando, 2008.

BARROWS, H.S.; TAMBLYN, R.M. Problem-based Learning in Medical Education. New York: Springer, 1980.

BERTUGLIA, C.S.; INFUSINO, S.; STAGHELLINI, A. I1 museo educativo. Milano: FrancoAngeli, 2004.

BLOOM, B.S. Caratteristiche umane e apprendimento scolastico. Roma: Armando, 1979.

BORTOLOTTI, A.; CALIDONI, M.; MASCHERONI, S.; MATTOZZZI, I. Per

l'educazione al patrimonio culturale. 22 tesi. Milano: FrancoAngeli, 2008.

BRUNER, J. La mente a più dimensioni. Bari: Laterza 1988.

BRUNER, J. La ricerca del significato. Per una psicologia culturale. Torino: Bollati Boringhieri, 1992.

BRUNER, J. La cultura dell'educazione. Nuovi orizzonti per la scuola. Milano: Feltrinelli, 2000.

CALIDONI, M.; CIRESOLA, E.; DI MAURO, A. La didattica museale. Roma: Aracne, 2006.

CARDONE, S. (a cura di). Formare al Museo. Arte, gioco e narrazione in Pinacoteca. Bari: Progedit, 2014. 
CIARCIÀ, P.; DALLARI, M. Arte per crescere. Idee, immagini, Laboratori. Bazzano: Artebambini, 2016.

COUNCIL OF EUROPE, Framework Convention on the Value of Cultural heritage for Society, article 7 (Cultural Heritage and Dialogue) and 8 (Environment, Heritage and Quality of Life), Faro 27.10.2005.

DALLARI, M.; FRANCUCCI, C. L'esperienza pedagogica dell'arte. Firenze: La Nuova Italia, 1990.

DE CARLI, C. (a cura di). Education through Art. Milano: Mazzotta, 2003.

DEWEY, J. L'arte come esperienza e altri scritti. Firenze: La Nuova Italia, 1995.

FALK, J.H.; DIERKING, L.D. Learning from Museums: Visitor Experiences and the Making of Meaning. Walnut Creek (CA): Altamira Press, 2000.

FALK, J.H.; DIERKING, L.D. The Museum Experience. Washington: Whalesback Books, 1992.

FRANCUCCI, C.; VASSALLI, P. (a cura di). Educare all'arte. Milano: Electa, Milano 2010.

GARDNER, H. Educare al comprendere. Milano: Feltrinelli,1999.

GARDNER, H. Educazione e sviluppo della mente. Intelligenze multiple e apprendimento. Trento: Erickson, 2005.

GIBBS, K.; SANI, M.; THOMPSON J. (a cura di). Musei e apprendimento lungo tutto l'arco della vita. Un manuale europeo. Ferrara: Edidai, 2007.

HEIN, G. E. The Constructivist Museum. Journal of education in Museums, n. 16, 1995.

HEIN, G. E. Learning in the museum. London, New York: Routledge, 1998.

HOOPER-GREENHILL, E. Museum, Media, Message. London: Routledge, 1995.

HOOPER-GREENHILL, E. The Educational Role of Museum. London: Routledge, 1999 .

HUERTA, R.; ALONSO-SANZ, A. (eds.). Entornos informales para educar en arte. Valencia: PUV, 2017.

LIMONE, P. (a cura di). Educazione, scuole e musei. Roma: Carocci, 2012.

LOTTI, A. (a cura di). Apprendere per problemi. Una sperimentazione didattica nelle facoltà umanistiche. Bari: Progedit, 2007.

LOLLOBRIGIDA, C. Introduzione alla museologia. Storia, strumenti e metodi per l'educatore museale. Firenze: Le Lettere, 2010.

MACDONALD, S. (a cura di). A Companion to Museum Studies. Malden: Blackwell, 2006. 
MARANI, P. C.; PAVONI, R. Musei. Trasformazioni di un'istituzione dall'età moderna al contemporaneo. Venezia: Marsilio, 2006.

MONACI, S. Il futuro nel museo. Come i nuovi media cambiano l'esperienza del pubblico. Milano: Guerini 2005.

MONTESSORI, M. La scoperta del bambino. Milano: Garzanti, 2000 (Original work published 1948).

MONTESSORI, M. La mente del bambino. Milano: Garzanti, 1987.

MUNARI, B. Fantasia. Roma-Bari: Laterza, 1977.

MUNARI, B. Laboratorio per bambini a Faenza. Bologna: Zanichelli, 1981.

MUNARI, B. I laboratori tattili. Mantova: Corraini, 1985.

NARDI, E. Musei e pubblico. Un rapporto educativo. Milano: Franco Angeli, 2004.

NARDI, E. Forme e messaggi del museo. Milano: Franco Angeli, 2011.

NUZZACI, A. Il museo come luogo di apprendimento. Lecce: Pensa Multimedia, 2008.

PRETE, C. Aperto al pubblico. Comunicazione e servizi educativi nei musei. Firenze: Edifir, 2005.

OFFICIAL JOURNAL OF THE EUROPEAN UNION, Recommendation of the European Parliament and of the Council of 18 December 2006 on key competences for lifelong learning (2006/962/EC).

RASTELLI, B. Giocare con tatto. Per una educazione plurisensoriale secondo il metodo Bruno Munari. Milano: FrancoAngeli, 2002.

RECOMMENDATION NO. R (98) - Heritage Education, adopted by the Committee of Ministers on 17 March 1998 at the 623rd meeting of the Ministers' Deputies.

SANI, M.; TROMBINI, A. (a cura di). La qualità nella pratica educativa al museo. Istituto per i beni artistici, culturali e naturali della Regione Emilia-Romagna. Bologna: Editrice Compositori, 2003.

VINELLA, M. Educazione ai beni culturali e ambientali. Dall'immagine al paesaggio, dall'ecomuseo alla città. Lecce: Pensa, 2004.

VISSER TRAVAGLI, A.M. "Le professioni della didattica museale e la gestione del servizio educativo" in ZERBINI, L. (a cura di). La didattica museale. Roma: Aracne, 2006.

VYGOTSKIJ, L. Psicologia pedagogica, Manuale di psicologia applicata all'insegnamento e all'educazione. Trento: Erickson, 2006. 